\title{
Fatty acid profiles and antioxidant properties of dabai oil
}

\author{
Nur Arina Ahmad Jelani ${ }^{\mathrm{a}}$, Azrina Azlan ${ }^{\mathrm{a}, \mathrm{b}, \mathrm{c}, *}$, Amin Ismail ${ }^{\mathrm{a}, \mathrm{b}, \mathrm{c}}$, Hock Eng Khoo ${ }^{\mathrm{a}, \mathrm{c}}$, \\ Suryati Mohd Alinafiah ${ }^{\mathrm{a}}$ \\ ${ }^{a}$ Department of Nutrition and Dietetics, Faculty of Medicine and Health Sciences, \\ Universiti Putra Malaysia, 43400 UPM Serdang, Selangor, Malaysia \\ b Laboratory of Halal Science Research, Halal Products Research Institute, Universiti Putra Malaysia, \\ 43400 UPM Serdang, Selangor, Malaysia \\ c Research Centre of Excellence for Nutrition and Non-Communicable Disease, \\ Faculty of Medicine and Health Sciences, Universiti Putra Malaysia, 43400 UPM Serdang, Selangor, \\ Malaysia \\ *Corresponding author, e-mail: azrinaaz@upm.edu.my
}

Received 9 Jun 2016

Accepted 4 Sep 2017

\begin{abstract}
Supercritical $\mathrm{CO}_{2}\left(\mathrm{SC}_{-} \mathrm{CO}_{2}\right)$ was used to extract dabai oil. Total phenolic content, total flavonoid content, DPPH radical scavenging assay, and gas chromatography analysis were performed to determine the antioxidant properties of $\mathrm{SC}_{-} \mathrm{CO}_{2}$-extracted dabai oil and to compare with hexane-extracted dabai oil. The total phenolic content of SC- $\mathrm{CO}_{2}$-extracted oil was slightly higher than hexane-extracted oil, whereas the total flavonoid content of $\mathrm{SC}-\mathrm{CO}_{2}$ extracted dabai oil was four times lower than the hexane-extracted oil. The percentage of radical scavenging activity for SC- $\mathrm{CO}_{2}$-extracted oil was $0.71 \%$, but the hexane-extracted oil had a higher radical scavenging activity of $3 \%$. Analysed using gas chromatography, $\mathrm{SC}-\mathrm{CO}_{2}$-extracted oil had lower total saturated fatty acids than the hexane-extracted oil.
\end{abstract}

KEYWORDS: Canarium odontophyllum, supercritical $\mathrm{CO}_{2}$, green technology

\section{INTRODUCTION}

Canarium odontophyllum Miq. is one of the plants found in the tropical rainforest of Sarawak. The fruit of $C$. odontopyllum is the most commonly consumed by the native people in Sarawak ${ }^{1}$. The fruit is wellknown as 'dabai' among local community ${ }^{2}$. Dabai fruits are white when they are still immature and then turn into a purplish pink and a powdery black colour once it ripens ${ }^{3}$. Its seed is subtriangular in shape with three chambers ${ }^{4}$. A mixture of two superior clones, namely Laja and Lulong which can be found mainly in Sarikei, Sarawak, were used for this study ${ }^{5}$. The cross section of the Laja clone shows a triangular seed with concave sides while the Lulong clone has a more rounded seed ${ }^{5}$. The locals usually soak the ripe fruit in warm water for 3-5 min to soften the flesh before consumption. Sometimes the fruit is eaten with seasoning such as sugar, salt, pepper, or sauce ${ }^{4}$.

Dabai is an oily fruit having about $25 \%$ of fat from only its pulp ${ }^{6}$. The fat content of dabai is comparable to that of avocado. Avocado is another fruit known to be high in fat, and studies discovered that avocado contains around 15-30\% of fat ${ }^{7,8}$. Dabai oil has similar characteristics with some commercially available edible oils. Literature reveals that plant oil is a better source of dietary lipid because it supplies a lower level of saturated fat and provides important dietary antioxidants like vitamin $\mathrm{E}$, and phenolic compounds ${ }^{9}$. The fatty acid constituents of a plant oil together with phytochemicals in the oil, which are responsible for its functionality plus health promoting properties ${ }^{1}$. A few studies have been previously determined for antioxidant properties of the dabai fruit. It was reported that the fatty acid compositions of dabai pulp and kernel oil samples, where palmitic (16:0), oleic (18:1) and linoleic (18:2) acids are the major fatty acids ${ }^{1}$. Besides, dabai pulp oil contains a fatty acid profile that is comparable to that of palm oil. Hence dabai pulp oil most probably can be used as an alternative choice as vegetable oil.

In the previous studies, dabai oil was extracted using organic solvents, such as hexane or petroleum ether. A green technology used in the extraction of oil, which is supercritical fluid extraction (SFE), may offer an alternate to produce a toxic-free dabai oil. 
Among the modern technologies used in oil extraction, SFE is undoubtedly the most extensively studied for its application. SFE is commonly performed using $\mathrm{CO}_{2}$ for several practical reasons, such as low critical temperature and pressure $\left(T_{\mathrm{c}}=31.1^{\circ} \mathrm{C} ; P_{\mathrm{c}}=\right.$ $72.8 \mathrm{~atm}) . \mathrm{CO}_{2}$ is not toxic and non-flammable, and it is also an inert gas that does not react with the food constituents ${ }^{10}$.

Supercritical $\mathrm{CO}_{2}$ has a polarity akin to liquid pentane and thus is applicable for extraction of lipophilic compounds. Due to the lipophilic characteristic of essential oils from plant, supercritical $\mathrm{CO}_{2}$ is the best candidate for extraction of these oils ${ }^{11}$. In this study, we aimed to extract the dabai using $\mathrm{SFE}$ and to compare the supercritical $\mathrm{CO}_{2}$ extracted dabai oil with hexane-extracted dabai oil for their fatty acid compositions. As the dabai fruit has high fat content and is rich in antioxidant properties with potential health benefits; hence we determined the antioxidant properties of supercritical $\mathrm{CO}_{2}$ extracted together with the fatty acid compositions.

\section{MATERIALS AND METHODS}

\section{Sample preparation}

Fresh dabai fruits were obtained from the selected dabai plantations in Sibu, Sarawak with the help of Sarawak Agriculture Research Centre. The dabai used for this study was a mixture of two superior clones, namely, Laja and Lulong which can be found mainly in Sarikei, Sarawak. The maturity of the dabai fruits used were determined by professional farmer of the dabai plantation and all fresh ripe fruits were packed in airtight chilling containers and shipped to Putra University Malaysia on the same day of fruit collection. All fruits were immediately stored at $-80^{\circ} \mathrm{C}$ freezer before sample preparation. Dabai kernel was removed, chilled and freeze dried. The lyophilised dabai pulp was ground into a powder form of 20 mesh particle size. The lyophilised powder was kept in an airtight container at $-20^{\circ} \mathrm{C}$ until further analyses.

\section{Supercritical fluid extraction}

Extraction of dabai oil was performed using a benchtop supercritical $\mathrm{CO}_{2}$ extractor from Supercritical Fluid Technologies Inc. (Model SFT-100). The extraction was carried out at a temperature of $24^{\circ} \mathrm{C}$, pressure of $60 \mathrm{MPa}$, and $40 \mathrm{~min}$ extraction time. Approximately $10.0 \mathrm{~g}$ of dabai powder was inserted into the extraction vessel. Extraction was carried out by injection the $\mathrm{CO}_{2}$ into the extraction chamber. After $40 \mathrm{~min}$, the oil was collected in an amber bottle. The oil obtained was kept in $-20^{\circ} \mathrm{C}$ until further analyses.

\section{Solvent extraction}

Approximately $8 \mathrm{~g}$ of dabai pulp powder was weighed into a conical flask and hexane was added at a ratio of 1:10 (pulp:hexane). The mixture was shaken well, and then the flask was wrapped in aluminium foil and stored at $4^{\circ} \mathrm{C}$ overnight $(24 \mathrm{~h})$. The hexane fraction was filtered using a Whatman No. 4 filter paper, and hexane was removed using a rotary evaporator and re-extracted with hexane. The extraction was repeated three times using the same ratio of 1:10. The oil obtained was stored in $-20^{\circ} \mathrm{C}$ until further analyses.

\section{Total flavonoid content}

Total flavonoid content (TFC) was determined based on a method described by previous literature $^{12}$ with some modifications. Approximately $500 \mu \mathrm{l}$ of dabai oil, $1.5 \mathrm{ml}$ of ethanol, $100 \mu \mathrm{l}$ of $\mathrm{Al}\left(\mathrm{NO}_{3}\right)_{3}, 100 \mu \mathrm{l}$ of potassium acetate $(1 \mathrm{M})$, and $2.8 \mathrm{ml}$ of distilled water were mixed into a test tube. The mixture was left to stand for $40 \mathrm{~min}$ at room temperature $\left(25^{\circ} \mathrm{C}\right)$. The mixture was then centrifuged at $3000 \mathrm{rpm}(1500 \mathrm{~g})$. Clear part of the mixture was collected and then absorbance was read at $415 \mathrm{~nm}$ using a spectrophotometer. The standard calibration curve was plotted based on absorbance versus concentrations of quercetin standard. TFC was calculated for each sample, and the result was expressed as mg quercetin equivalent of sample ( $\mathrm{mg}$ $\mathrm{QE} / \mathrm{g}$ sample).

\section{Total phenolic content}

Total phenolic content (TPC) was determined based on a colourimetric method ${ }^{13}$. About $0.5 \mathrm{~g}$ dabai oil was dissolved in $1 \mathrm{ml}$ of hexane, and the phenolic compounds were extracted with $0.6 \mathrm{ml}$ methanol/water (60:40 v/v) using an orbital shaker for $2 \mathrm{~min}$. The mixture was centrifuged at $3500 \mathrm{rpm}$ $(2100 \mathrm{~g})$ for $10 \mathrm{~min}$, and the hexane phase was reextracted with $0.6 \mathrm{ml}$ methanol/water $(60: 40 \mathrm{v} / \mathrm{v})$. The methanolic extract solutions were pooled, and an aliquot of $0.2 \mathrm{ml}$ of the methanolic phase was diluted with distilled water to a total volume of $2.5 \mathrm{ml}$.

Next, $0.25 \mathrm{ml}$ of Folin-Ciocalteu reagent was added. After $3 \mathrm{~min}$ of incubation at room temperature $\left(25^{\circ} \mathrm{C}\right), 0.5 \mathrm{ml}$ of $\mathrm{Na}_{2} \mathrm{CO}_{3}$ solution $(35 \%$, $\mathrm{w} / \mathrm{v}$ ) was added to the mixture, which was finally top-up with distilled water to $5 \mathrm{ml}$. Absorbance of the solution was measured exactly after $2 \mathrm{~h}$ 
against a blank sample using the spectrophotometer at a wavelength of $725 \mathrm{~nm}$. A calibration curve was obtained based on different concentrations of gallic acid standard, and the result was expressed as mg gallic acid equivalent per g sample (mg GAE/g sample).

\section{DPPH assay}

DPPH (2,2-diphenyl-1-picrylhydrazyl) radical scavenging activity was conducted based on the electron-transfer reaction method as described by previous literature ${ }^{14}$. Briefly, $1 \mathrm{ml}$ of dabai oil extract was mixed with $2 \mathrm{ml}$ of $10 \mu \mathrm{g} / \mathrm{ml} \mathrm{DPPH}$ solution in methanol. The mixture was then shaken vigorously and left to stand at room temperature for $5 \mathrm{~min}$. The decrease in absorbance was recorded at $517 \mathrm{~nm}$ using methanol as a control. The DPPH radical scavenging activity of the extract was calculated as $1-$ (absorbance of sample/absorbance of control).

\section{Determination of fatty acid composition}

Fatty acid methyl esters of the studied oil samples were prepared based on the method described by a previous study ${ }^{1}$. Briefly, $0.1 \mathrm{~g}$ dabai oil was weighed into a test tube. The sample was dissolved by adding $10 \mathrm{ml}$ of hexane and $100 \mu \mathrm{l}$ of $\mathrm{KOH}(2 \mathrm{M})$. The test tube was capped and vortexed for $30 \mathrm{~s}$. The mixture was then centrifuged at $402 \mathrm{~g}$ for about $10 \mathrm{~min}$; the extracts were transferred into an autosampler vial and analysed by the gas chromatography-flame ionization detector to determine the fatty acid composition of the dabai oil.

\section{Gas chromatography condition}

The GC system (Agilent 6890, Wilmongton DE, USA) used was equipped with a split-splitless injector. Hewlett-Packard EL-980 flame ionization detection (FID) system was used to separate and quantify each FAME component which were separated using the DB-23 column $(60 \mathrm{~m} \times 0.25 \mathrm{~nm}$, i.d. $0.15 \mu \mathrm{m}$ polyethylene glycol film) (Muskegon, MI, USA). Oven temperature was set at $50^{\circ} \mathrm{C}$ for $1 \mathrm{~min}$ and further increased to $175^{\circ} \mathrm{C}$ at $4 \mathrm{C} / \mathrm{min}$ and increased to $230^{\circ} \mathrm{C}$ which was held for $5 \mathrm{~min}$. The injector and detector temperature used were $250^{\circ} \mathrm{C}$ and $280^{\circ} \mathrm{C}$. Oil sample of $1 \mu \mathrm{l}$ was injected with split ratio of $1: 50$ at column temperature of $110^{\circ} \mathrm{C}$. Helium $(1 \mathrm{ml} / \mathrm{min})$ was used as carrier gas controlled at $103.4 \mathrm{kPa}$ while hydrogen and air was used for FID and held at $275.6 \mathrm{kPa}$. FAME standards were used for the identification of the fatty acids.

\section{Statistical analysis}

Triplicate determinations were done for each analysis. All data were expressed as mean \pm standard deviation. Significant differences in the fatty acid profiles and antioxidant properties between hexane and supercritical $\mathrm{CO}_{2}\left(\mathrm{SC}-\mathrm{CO}_{2}\right)$ extractions were analysed by one sample $t$-test using SPSS 21, where the statistical significance level was set at $p<0.05$.

\section{RESULTS AND DISCUSSION}

\section{Yield}

The result showed that there was a significant difference $(p<0.05)$ in the oil yield between hexane and SC- $\mathrm{CO}_{2}$ extraction methods employed. The percentage of oil (51\%) obtained by hexane extraction was almost twice as high as the $\mathrm{SC}-\mathrm{CO}_{2}$ extraction $(23 \%)$. Unlike the SC- $\mathrm{CO}_{2}$ extraction method, the lipid soluble substances together with triacylglycerols are basically more soluble in hexane ${ }^{15}$.

A previous study revealed that extraction of oil from oleaginous fungus, Mortierella alpine, using hexane had a higher percentage of oil extracted than the $\mathrm{SC}-\mathrm{CO}_{2}$ method ${ }^{15}$. Hexane also differs from $\mathrm{CO}_{2}$ because it is non-selective for triglycerides, causing it to extract almost all available fatty acids, pigments, phospholipids and unsaponifiable substances along with triglycerides ${ }^{16}$. The fact explains why the yield of organic solvent extraction is higher than that of SC-CO extraction $^{16}$.

Pressure plays a significant role in affecting the percentage of extracted oil. A high pressure can significantly increase the oil yield ${ }^{17}$. At lower extraction pressure, the solubility of oil is affected by the vapour pressure of oil. Also, $\mathrm{CO}_{2}$ acts as an ideal gas that does not have special properties of a solvent at lower pressure. At higher pressures, the solubility of oil increases due to the increase density of $\mathrm{CO}_{2}{ }^{17}$. The increase in $\mathrm{CO}_{2}$ density will reduce the distance between the molecules of $\mathrm{CO}_{2}$ and oil, and the interaction between these molecules increase, thus increase the solubility of oil in $\mathrm{CO}_{2}$.

\section{Total phenolic content}

TPC of dabai oils extracted using hexane and SC- $\mathrm{CO}_{2}$ was determined based on the colourimetric method. Dabai oil extracted by SC$\mathrm{CO}_{2}$ demonstrated a non-significantly higher TPC $(0.733 \pm 0.009 \mathrm{mg} \mathrm{GAE} / \mathrm{g})$ than the hexane-extracted oil $(0.679 \pm 0.002 \mathrm{mg} \mathrm{GAE} / \mathrm{g})$, with $p=$ 0.069 . The result is in contrast to the finding reported by a previous study that phenolic compounds were not detected in $\mathrm{SC}^{-\mathrm{CO}_{2}}$-extracted peach palm 
pulp (Bactris gasipaes) ${ }^{18}$. A possible explanation for this finding is the hydrophobic nature of SC- $\mathrm{CO}_{2}$ that solubilised and extracted almost all non-polar molecules. Hence SC- $\mathrm{CO}_{2}$ extraction is not an ideal way to extract phenolic compounds ${ }^{19,20}$.

There are several other ways to increase the amount of phenolics extracted from plants. An increase in operation time can facilitate extraction of higher molecular weight compounds, such as polyphenols because these compounds need a longer time to be solubilised in the extraction solution $^{19}$. Besides that the addition of co-solvents such as ethanol has been found successfully to improve the $\mathrm{SC}-\mathrm{CO}_{2}$ extraction of phenolic compounds in grape samples ${ }^{21}$.

On the other hand, an increase in extraction pressure can improve the extraction yield. A higher phenolic content can be obtained in the extract of berries pressing wastes by applying a higher pressure (200 bar or higher) during supercritical extraction ${ }^{19}$. Different sample matrices of plants might need different optimal extraction pressures for extracting phenolic components. Furthermore, other organic compounds could also be extracted at a higher extraction pressure, resulting in slight increase in TPC of dabai oil extracted using SC- $\mathrm{CO}_{2}$.

\section{Total flavonoid content}

TFC of dabai oil extracted using hexane and SC$\mathrm{CO}_{2}$ was also determined based on colorimetric method. The TFC of hexane-extracted dabai oil $(53.45 \pm 0.07 \mathrm{mg} \mathrm{QE} / \mathrm{g})$ was significantly higher than the $\mathrm{SC}_{-} \mathrm{CO}_{2}$-extracted dabai oil $(12.6 \pm 1.1 \mathrm{mg}$ $\mathrm{QE} / \mathrm{g}$ ). A previous study revealed that TFC was not detected in the $\mathrm{SC}-\mathrm{CO}_{2}$ extract of peach palm pulp sample ${ }^{18}$. This finding explains the low TFC in SC$\mathrm{CO}_{2}$-extracted oil. The amount of phytochemicals obtained is largely affected by the extraction temperature and pressure using $\mathrm{SC}-\mathrm{CO}_{2}{ }^{22}$. Extraction time may also influence the extraction yield, especially within the first 90 min of extraction ${ }^{23}$.

\section{DPPH radical scavenging activity}

DPPH radical scavenging assay was used to evaluate the antioxidant activity of the dabai oil extracts. The extract of hexane-extracted dabai oil (3\%) exhibited a significantly higher radical scavenging activity $(p<0.01)$ than the extract of SC- $\mathrm{CO}_{2}$-extracted dabai oil $(0.71 \%)$. The extraction of oil using Soxhlet extraction showed a low antioxidant profile, which could be due to the weak interaction between hexane and antioxidant components ${ }^{24}$. The fact may explain that the extract of hexane-extracted dabai oil has little radical scavenging activity. However, a modifier such as ethanol added to the extraction solvent could increase the DPPH antiradical power ${ }^{21}$.

Conversely, a previous study reported that Rosmarinus officinalis extract obtained from $\mathrm{SC}^{-} \mathrm{CO}_{2}$ extraction has higher DPPH radical scavenging activity $(62 \%)$ than the hexane extract $(57 \%)^{25}$. A possible explanation for the low radical scavenging activity of the extract of $\mathrm{SC}_{-} \mathrm{CO}_{2}$-extracted dabai oil is the high pressure applied during $\mathrm{SC}-\mathrm{CO}_{2}$ extraction, and it might also be due to the hydrophobic characteristic of $\mathrm{CO}_{2}$ that reduced the extractability of hydrophilic antioxidant compounds. Thus the $\mathrm{SC}-\mathrm{CO}_{2}$-extracted oil extract has a low percentage of antioxidant activity ${ }^{26}$. Interestingly, DPPH radical scavenging activity is strongly correlated with $\mathrm{TFC}^{27}$. Hence the results obtained from this study also revealed a correlation between TFC and DPPH radical scavenging activity.

\section{Fatty acid profile}

Fatty acid compositions $(\mathrm{mg} / \mathrm{g}$ ) of dabai oil obtained from hexane and $\mathrm{SC}-\mathrm{CO}_{2}$ extraction are shown in Tables 1-3. The results also revealed that both hexane and $\mathrm{SC}-\mathrm{CO}_{2}$-extracted oils have high percentages of total saturated fatty acid (SFA), 90\% and $86 \%$, respectively. Among the SFA, palmitic acid (16:0), heneicosylic acid (21:0) and margaric acid (17:0) are the most abundant. The major MUFAs in the extracted dabai oil were myristoleic acid (C14:1) and heptadecenoic acid (C17:1), while brassic acid (C22:2), eicosadienoic acid (C20:2), and gammalinolenic acid (C18:3n6) were the main PUFA in the extracted oil.

In this study, the hexane-extracted dabai was found to contain a higher total SFA than the $\mathrm{SC}-\mathrm{CO}_{2}$ extracted oil. In contrast, the $\mathrm{SC}-\mathrm{CO}_{2}$-extracted oil had higher total MUFA and total PUFA than the hexane-extracted oil. Among the types of SFA, arachidic acid, behenic acid, tricosylic acid, and lignoceric acid were not detected in the $\mathrm{SC}-\mathrm{CO}_{2}-$ extracted dabai oil. The result indicated that a long-chain arachidic acid and all very long-chain fatty acids were not found in the $\mathrm{SC}-\mathrm{CO}_{2}$-extracted dabai oil. Conversely, hexane-extracted dabai oil consisted a very long-chain behenic acid. Also, the hexane-extracted oil had a higher percentage of total medium-chain fatty acids (3\%) than the SC$\mathrm{CO}_{2}$-extracted oil (2\%).

Among the types of MUFA, SC- $\mathrm{CO}_{2}$-extracted dabai oil had higher percentages of myristoleic acid, pentadecylic acid, oleic acid, and gondoic acid than 
Table 1 Saturated fatty acid (SFA) content of hexane-extracted and SC- $\mathrm{CO}_{2}$-extracted dabai oil.

\begin{tabular}{|c|c|c|c|c|c|}
\hline \multirow[t]{2}{*}{ Common name } & \multirow[t]{2}{*}{ Fatty acid } & \multicolumn{2}{|c|}{ Hexane } & \multicolumn{2}{|c|}{$\mathrm{SC}-\mathrm{CO}_{2}$} \\
\hline & & $\mathrm{mg} / \mathrm{g}$ oil & $\%{ }^{*}$ & $\mathrm{mg} / \mathrm{g}$ oil & $\% *$ \\
\hline Butyric acid & $\mathrm{C} 4: 0$ & $0.148 \pm 0.028$ & 0.78 & $0.206 \pm 0.141$ & 1.09 \\
\hline Caproic acid & C6:0 & $0.442 \pm 0.056$ & 2.32 & $0.218 \pm 0.009$ & 1.15 \\
\hline Caprylic acid & C8:0 & $0.110 \pm 0.014$ & 0.58 & $0.094 \pm 0.003$ & 0.50 \\
\hline Capric acid & C10:0 & $0.038 \pm 0.003$ & 0.20 & $0.066 \pm 0.006$ & 0.35 \\
\hline Undecylic acid & $\mathrm{C} 11: 0$ & $0.008 \pm 0.006$ & 0.04 & $0.019 \pm 0.005$ & 0.10 \\
\hline Lauric acid & $\mathrm{C} 12: 0$ & $0.033 \pm 0.006$ & 0.17 & $0.057 \pm 0.008$ & 0.30 \\
\hline Tridecylic acid & C13:0 & $0.024 \pm 0.001$ & 0.13 & $0.038 \pm 0.012$ & 0.20 \\
\hline Myristic acid & $\mathrm{C} 14: 0$ & $0.032 \pm 0.002$ & 0.17 & $0.060 \pm 0.049$ & 0.32 \\
\hline Pentadecylic acid & C15:0 & ND & 0 & $0.021 \pm 0.001$ & 0.11 \\
\hline Palmitic acid & C16:0 & $12.6 \pm 2.2$ & 66.1 & $11.096 \pm 0.274$ & 58.7 \\
\hline Margaric acid & $\mathrm{C} 17: 0$ & $1.563 \pm 0.245$ & 8.21 & $1.994 \pm 0.584$ & 10.5 \\
\hline Stearic acid & C18:0 & $0.069 \pm 0.045$ & 0.36 & $0.098 \pm 0.004$ & 0.52 \\
\hline Nonadecylic acid & C19:0 & $0.307 \pm 0.050$ & 1.61 & $0.324 \pm 0.105$ & 1.71 \\
\hline Arachidic acid & C20:0 & $0.231 \pm 0.176$ & 1.21 & ND & 0 \\
\hline Heneicosylic acid & $\mathrm{C} 21: 0$ & $1.566 \pm 0.252$ & 8.22 & $1.920 \pm 0.537$ & 10.2 \\
\hline Behenic acid & $\mathrm{C} 22: 0$ & $0.026 \pm 0.001$ & 0.13 & ND & 0 \\
\hline Tricosylic acid & $\mathrm{C} 23: 0$ & ND & 0 & ND & 0 \\
\hline Lignoceric acid & $\mathrm{C} 24: 0$ & ND & 0 & ND & 0 \\
\hline Total SFA & & 17.187 & 90.2 & 16.211 & 85.7 \\
\hline
\end{tabular}

" The percentage of fatty acids is calculated based on the total fatty acids determined by gas chromatographic analysis. $\mathrm{ND}=$ not detected.

Table 2 Monounsaturated fatty acid (MUFA) content of hexane-extracted and SC- $\mathrm{CO}_{2}$-extracted dabai oil.

\begin{tabular}{|c|c|c|c|c|c|}
\hline \multirow[t]{2}{*}{ Common name } & \multirow[t]{2}{*}{ Fatty acids } & \multicolumn{2}{|c|}{ Hexane } & \multicolumn{2}{|c|}{$\mathrm{SC}-\mathrm{CO}_{2}$} \\
\hline & & $\mathrm{mg} / \mathrm{g}$ oil & $\% *$ & $\mathrm{mg} / \mathrm{g}$ oil & $\% *$ \\
\hline Myristoleic acid & C14:1 & $0.437 \pm 0.070$ & 2.29 & $0.571 \pm 0.107$ & 3.02 \\
\hline Pentadecylic acid & C15:1 & $0.105 \pm 0.012$ & 0.55 & $0.121 \pm 0.008$ & 0.64 \\
\hline Palmitoleic acid & C16:1 & ND & 0 & ND & 0 \\
\hline Heptadecenoic acid & $\mathrm{C} 17: 1$ & $0.382 \pm 0.053$ & 2.01 & $0.352 \pm 0.047$ & 1.86 \\
\hline Oleic acid & C18:1n9t & $0.019 \pm 0.001$ & 0.10 & $0.021 \pm 0.001$ & 0.11 \\
\hline Gondoic acid & C20:1n9 & ND & 0 & $0.050 \pm 0.019$ & 0.26 \\
\hline Erucic acid & C22:1n9 & ND & 0 & ND & 0 \\
\hline Nervonic acid & $\mathrm{C} 24: \ln 9$ & $0.121 \pm 0.054$ & 0.64 & $0.100 \pm 0.072$ & 0.53 \\
\hline Total MUFA & & 1.064 & 5.59 & 1.215 & 6.42 \\
\hline
\end{tabular}

" The percentage of fatty acids is calculated based on the total fatty acids determined by gas chromatographic analysis. $\mathrm{ND}=$ not detected.

the hexane-extracted oil. Palmitoleic acid and erucic acid were not detected in both hexane and $\mathrm{SC}-\mathrm{CO}_{2}-$ extracted dabai oils. The percentages of all individual type of PUFAs of $\mathrm{SC}-\mathrm{CO}_{2}$-extracted dabai oil were higher than the hexane-extracted oil. Hence we found no docosahexaenoic acid in the hexaneextracted dabai oil. Furthermore, a lower ratio of omega-6/omega-3 was also calculated for the SC$\mathrm{CO}_{2}$-extracted dabai oil (1.1:1) than the hexaneextracted oil (3.4:1), as well as other vegetable oils ( $>5: 1$ ). The omega-6/omega-3 ratio in food is important for prevention of several chronic diseases ${ }^{28}$.
A previous study reported that dabai pulp has a high total saturated fatty acids ${ }^{1}$. In this study, we conclude that the total MUFA and total PUFA in the $\mathrm{SC}-\mathrm{CO}_{2}$-extracted dabai oil were higher than the hexane-extracted oil. On the contrary, a study reported that flaxseed oil extracted using organic solvent contained higher SFA than the SFE method ${ }^{29}$. The conventional lipid extraction method including hexane extraction may cause deterioration of PUFA due to the high processing temperature ${ }^{30}$. SFE has been used for preserving PUFA because the extraction can be conducted at a lower temperature ${ }^{30}$. 
Table 3 Polyunsaturated fatty acid (PUFA) content of hexane-extracted and $\mathrm{SC}-\mathrm{CO}_{2}$-extracted dabai oil.

\begin{tabular}{|c|c|c|c|c|c|}
\hline \multirow[t]{2}{*}{ Common name } & \multirow[t]{2}{*}{ Fatty acids } & \multicolumn{2}{|c|}{ Hexane } & \multicolumn{2}{|c|}{$\mathrm{SC}-\mathrm{CO}_{2}$} \\
\hline & & $\mathrm{mg} / \mathrm{g}$ oil & $\%{ }^{*}$ & $\mathrm{mg} / \mathrm{g}$ oil & $\% "$ \\
\hline Linoleic acid & $\mathrm{C} 18: 2 \mathrm{n} 6 \mathrm{c}$ & ND & 0 & ND & 0 \\
\hline Linolelaidic acid & $\mathrm{C} 18: 2 \mathrm{n} 6 \mathrm{t}$ & ND & 0 & ND & 0 \\
\hline Alpha-linolenic acid & C18:3n3 & $0.037 \pm 0.001$ & 0.19 & $0.065 \pm 0.005$ & 0.34 \\
\hline Gamma-linolenic acid & C18:3n6 & $0.126 \pm 0.003$ & 0.66 & $0.189 \pm 0.002$ & 1.00 \\
\hline Eicosadienoic acid & C20:2 & $0.319 \pm 0.065$ & 1.68 & $0.329 \pm 0.022$ & 1.74 \\
\hline Dihomo- $\gamma$-linolenic acid & C20:3n6 & ND & 0 & ND & 0 \\
\hline Eicosatrienoic acid & C20:3n3 & ND & 0 & ND & 0 \\
\hline Arachidonic acid & C20:4n6 & ND & 0 & ND & 0 \\
\hline Eicosapentaenoic acid & C20:5n3 & ND & 0 & ND & 0 \\
\hline Brassic acid & $\mathrm{C} 22: 2$ & $0.315 \pm 0.359$ & 1.65 & $0.804 \pm 0.331$ & 4.25 \\
\hline Docosahexaenoic acid & C22:6n3 & ND & 0 & $0.102 \pm 0.047$ & 0.54 \\
\hline Total PUFA & & 0.797 & 4.18 & 1.489 & 7.87 \\
\hline
\end{tabular}

" The percentage of fatty acids is calculated based on the total fatty acids determined by gas chromatographic analysis. $\mathrm{ND}=$ not detected.

Interestingly, a study reported no significant difference in the fatty acid compositions of grape seed oil extracted using SC- $\mathrm{CO}_{2}$ and hexane ${ }^{16}$. However, the study revealed that different extraction time applied in the $\mathrm{SC}-\mathrm{CO}_{2}$ extraction could slightly alter the fatty acid composition of grape seed oil. This observation could be due to the fractionation of oil by depressurisation, which allowed the production of various grades of oil with different compositions of fatty acids. Freeze-drying of a plant sample before lipid extraction can ensure effective moisture removal and enable a higher lipid retrieval due to better cell wall disruption ${ }^{15}$.

\section{CONCLUSIONS}

Dabai pulp oil had a high SFA, especially extracted using hexane. Regarding extraction yield, the organic solvent was proven to be a more preferred extraction solvent for extracting fatty acids compared to $\mathrm{SC}-\mathrm{CO}_{2} . \quad \mathrm{SC}-\mathrm{CO}_{2}$-extracted dabai pulp oil had higher percentages of total medium-chain fatty acid and contained slightly higher TPC than the hexaneextracted oil. However, it had lower TFC and radical scavenging activity than the hexane-extracted oil. The fatty acid profile of this $\mathrm{SC}-\mathrm{CO}_{2}$-extracted oil was superior to the hexane-extracted oil because it contained higher percentages of MUFA and PUFA. In a nutshell, $\mathrm{SC}-\mathrm{CO}_{2}$ extraction is potentially a more acceptable extraction method due to the quality of fatty acids obtained. $\mathrm{CO}_{2}$ is also environmentally friendly and produces a non-toxic dabai oil. In the future, phytochemical profile of dabai oil is needed to be determined for ensuring the quality of SC- $\mathrm{CO}_{2}$ extracted dabai pulp oil.
Acknowledgements: This study was financially supported by the university's research grant (Geran Penyelidikan Pembangunan Inovasi, vote 9449700), Universiti Putra Malaysia.

\section{REFERENCES}

1. Azlan A, Prasad KN, Khoo HE, Abdul-Aziz N, Mohamad A, Ismail A, Amom Z (2010) Comparison of fatty acids, vitamin $\mathrm{E}$ and physicochemical properties of Canarium odontophyllum Miq. (dabai), olive and palm oils. J Food Compos Anal 23, 772-6.

2. Lau CY (2009) Development of indigenous fruit crops in Sarawak. A case study on dabai fruit. In: Proceedings of the National Conference on New Crops and Bioresources, pp 15-20.

3. Ding P (2011) Dabai (Canarium odontophyllum Miq). In: Yahia E (ed) Postharvest Biology and Technology of Tropical and Subtropical Fruits, pp 34-40, 41e-42e.

4. Chew LY, Khoo HE, Amin I, Azrina A, Lau CY (2012) Analysis of phenolic compounds of dabai (Canarium odontophyllum Miq.) fruits by high-performance liquid chromatography. Food Anal Meth 5, 126-37.

5. Brooke P, Lau CY, Razili RM (2013) Experience in commercializing Canarium odontophyllum Miq: A potential superfruit of Sarawak. In: International Symposium on Superfruits: Myth or Truth?, Ho Chi Minh City, Vietnam.

6. Chew LY, Prasad KN, Amin I, Azrina A, Lau CY (2011) Nutritional composition and antioxidant properties of Canarium odontophyllum Miq. (dabai) fruits. J Food Compos Anal 24, 670-7.

7. Bora PS, Narain N, Rocha RVM, Paulo MQ (2001) Characterization of the oils from the pulp and seeds of avocado (cultivar: Fuerte) fruits. Grasas Aceites 52, 171-4.

8. Naveh E, Werman MJ, Sabo E, Neeman I (2002) 
Defatted avocado pulp reduces body weight and total hepatic fat but increases plasma cholesterol in male rats fed diets with cholesterol. J Nutr 132, 2015-8.

9. Foster R, Williamson CS, Lunn J (2009) Culinary oils and their health effects. Nutr Bull 34, 4-47.

10. Sonsuzer S, Sahin S, Yilmaz L (2004) Optimization of supercritical $\mathrm{CO}_{2}$ extraction of Thymbraspicata oil. J Supercrit Fluid 30, 189-99.

11. Fornari T, Vicente G, Vázquez E, García-Risco MR, Reglero $G$ (2012) Isolation of essential oil from different plants and herbs by supercritical fluid extraction. J Chrom A 1250, 34-48.

12. Jia Z, Tang M, Wu J (1999) The determination of flavonoid contents in mulberry and their scavenging effects on superoxide radicals. Food Chem 64, 555-9.

13. Fuentes E, Báez ME, Bravo M, Cid C, Labra F (2012) Determination of total phenolic content in olive oil samples by UV-visible spectrometry and multivariate calibration. Food Anal Meth 5, 1311-9.

14. Ghafoor K, Al-Juhaimi FY, Choi YH (2012) Supercritical fluid extraction of phenolic compounds and antioxidants from grape (Vitis labrusca B.) seeds. Plant Foods Hum Nutr 67, 407-14.

15. Nisha A, Sankar KU, Venkateswaran G (2012) Supercritical $\mathrm{CO}_{2}$ extraction of Mortierella alpina single cell oil: Comparison with organic solvent extraction. Food Chem 133, 220-6.

16. Molero Gómez A, Pereyra López C, Martinez de la Ossa E (1996) Recovery of grape seed oil by liquid and supercritical carbon dioxide extraction: a comparison with conventional solvent extraction. Chem Eng J Biochem Eng J 61, 227-31.

17. Majdi S, Barzegar M, Jabbari A, Agha Alikhani M (2012) Supercritical fluid extraction of tobacco seed oil and its comparison with solvent extraction methods. J Agr Sci Tech 14, 1053-65.

18. Espinosa-Pardo FA, Martinez J, Martinez-Correa HA (2014) Extraction of bioactive compounds from peach palm pulp (Bactris gasipaes) using supercritical $\mathrm{CO}_{2}$. J Supercrit Fluid 93, 2-6.

19. Laroze LE, Díaz-Reinoso B, Moure A, Zúñiga ME, Domínguez H (2010) Extraction of antioxidants from several berries pressing wastes using conventional and supercritical solvents. Eur Food Res Tech 231, 669-77.

20. Martinez-Correa HA, Cabral FA, Magalhães PM, Queiroga CL, Godoy AT, Sánchez-Camargo AP, Paviani LC (2012) Extracts from the leaves of Baccharis dracunculifolia obtained by a combination of extraction processes with supercritical $\mathrm{CO}_{2}$, ethanol and water. J Supercrit Fluid 63, 31-9.

21. Pinelo M, Ruiz-Rodríguez A, Sineiro J, Señoráns FJ, Reglero G, Núñez MJ (2007) Supercritical fluid and solid-liquid extraction of phenolic antioxidants from grape pomace: a comparative study. Eur Food Res Tech 226, 199-205.

22. Rahmawati A, Pang D, Ju YH, Soetaredjo FE, Ki
OL, Ismadji S (2015) Supercritical $\mathrm{CO}_{2}$ extraction of phytochemical compounds from Mimosa pudica Linn. Chem Eng Comm 202, 1011-7.

23. Xu X, Gao Y, Liu G, Wang Q, Zhao J (2008) Optimization of supercritical carbon dioxide extraction of sea buckthorn (Hippophae thamnoides L.) oil using response surface methodology. LWT Food Sci Tech 41, 1223-31.

24. Michielin EM, de Lemos Wiese LP, Ferreira EA, Pedrosa RC, Ferreira SR (2011) Radical-scavenging activity of extracts from Cordia verbenacea DC obtained by different methods. J Supercrit Fluid 56, 89-96.

25. Rodríguez-Solana R, Salgado JM, Domínguez JM, Cortés-Diéguez S (2015) Comparison of soxhlet, accelerated solvent and supercritical fluid extraction techniques for volatile (GC-MS and GC/FID) and phenolic compounds (HPLC-ESI/MS/MS) from Lamiaceae species. Phytochem Anal 26, 61-71.

26. Kitzberger CSG, Smânia A, Pedrosa RC, Ferreira SRS (2007) Antioxidant and antimicrobial activities of shiitake (Lentinula edodes) extracts obtained by organic solvents and supercritical fluids. J Food Eng 80, 631-8.

27. Bakar MFA, Mohamed M, Rahmat A, Fry J (2009) Phytochemicals and antioxidant activity of different parts of bambangan (Mangifera pajang) and tarap (Artocarpus odoratissimus). Food Chem 113, 479-83.

28. Simopoulos AP (2002) Omega-3 fatty acids in wild plants, nuts and seeds. Asia Pac J Clin Nutr 11 (s6), S163-73.

29. Pradhan RC, Meda V, Rout PK, Naik S, Dalai AK (2010) Supercritical $\mathrm{CO}_{2}$ extraction of fatty oil from flaxseed and comparison with screw press expression and solvent extraction processes. J Food Eng 98, 393-7.

30. Cheng CH, Du TB, Pi HC, Jang SM, Lin YH, Lee HT (2011) Comparative study of lipid extraction from microalgae by organic solvent and supercritical $\mathrm{CO}_{2}$. Bioresour Tech 102, 10151-3. 